\title{
Genomic in situ hybridization identifies parental chromosomes in the wild grass hybrid $\times$ Festulpia hubbardii
}

\author{
JOHN P. BAILEY*1, SIMON T. BENNETT † , MICHAEL D. BENNETT $\dagger \&$ CLIVE A. STACE* \\ *Department of Botany, University of Leicester, Leicester LE1 7RH and †Jodrell Laboratory, Royal Botanic Gardens, \\ Kew, Richmond, Surrey TW9 3DS, UK
}

\begin{abstract}
Genomic in situ hybridization (GISH) was used to discriminate between the parental chromosomes of the grass $\times$ Festulpia hubbardii $(2 n=5 x=35 \pm 2 \mathrm{~B})$, a naturally occurring pentaploid hybrid between Festuca rubra $(2 n=6 x=42 \pm 2 B)$ and Vulpia fasciculata $(2 n=4 x=28)$. Biotinylated total genomic DNA of $V$. fasciculata, mixed with an excess of unlabelled $F$. rubra genomic DNA as a block, hybridized preferentially in situ to mitotic Vulpia chromosomes. Unlike Giemsa C-banding, which provided a physical marker only for the terminal regions of the parental chromosomes, GISH unequivocally identified chromatin from all regions along every Vulpia chromosome. Clearly, GISH has the potential for testing the theory that Vulpia genetic material has been transferred into Festuca rubra populations by introgressive hybridization. Genomic probing also discriminated between homogenetic (Vulpia-Vulpia and Festuca-Festuca) and heterogenetic (Vulpia-Festuca) bivalents, showing that GISH can aid the interpretation of chromosome behaviour in meiotic nuclei of hybrids.
\end{abstract}

Keywords: Festuca rubra, $\times$ Festulpia, genomic in situ hybridization (GISH), grass hybrids, introgressive hybridization, Vulpia fasciculata.

\section{Introduction}

Interspecific hybridization is a major force in flowering plant evolution. The relatively high incidence of natural hybridization in the grasses is well known; 57 different interspecific combinations have been found in Britain alone (Stace, 1991).

Festuca L. is a widespread genus of perennial, outbreeding, temperate grasses with probably over 300 species. Festuca rubra L. is a very variable species which is important both ecologically (being a major constituent of North-temperate grassland) and economically (second in Britian only to Lolium in terms of tonnage of turf-grass seed production). It is part of a complex aggregate of fine-leaved taxa, chiefly of North-temperate Eurasia and America, and especially characteristic of maritime habitats, dominating large areas of sand-dune, cliff-top and salt-marsh vegetation.

\footnotetext{
${ }^{1}$ Correspondence.

$\ddagger$ Present address: Nuffield Department of Surgery, University of Oxford, John Radcliffe Hospital, Headington, Oxford OX3 9DU, UK.
}

Vulpia C. C. Gmelin is a closely related genus of about 20 mostly annual, inbreeding species found in Europe, western Asia and temperate North and South America. In western and north-western Europe five species, including $V$. fasciculata (Forsskål) Fritsch, are characteristic of maritime sandy regions, where they commonly occur in close proximity to Festuca rubra. Four combinations of intergeneric hybrids between members of the $F$. rubra aggregate and species of Vulpia have been found in such habitats in England (Stace, 1991).

This paper concerns the hybrid Festuca rubra $\times$ Vulpia fasciculata $=\times$ Festulpia hubbardii Stace \& Cotton, which is frequent in southern Britain as far north as S. Lancashire and in the Channel Islands (Ainscough et al., 1986). Vulpia fasciculata is a semichasmogamous, self-compatible species; isolated plants produce a full seed-set and, in the wild, plants probably produce a negligible pollen-rain and are highly inbreeding. In contrast, Festuca rubra is highly (though not fully) self-incompatible (Auquier, 1977) and produces an abundant pollen-rain, so wild intergeneric hybrids are almost certainly derived from female Vulpia $\times$ male Festuca. The hybrid was produced artifi- 
cially with great ease but only in the latter direction (Stace \& Cotton, 1974). As Vulpia fasciculata is a tetraploid $(2 n=4 x=28)$ and the Festuca rubra involved in these crosses a hexaploid $(2 n=6 x=42)$, the hybrid $\times F$. hubbardii genome $(2 n=5 x=35)$ consists of 14 Vulpia and 21 Festuca chromosomes in a Vulpia cytoplasm. Some plants of $F$. rubra and $\times F$. hubbardii possess one or two B-chromosomes, as did some of the present material (Table 1).

Meiosis in the pentaploid wild $\times$ Festulpia is mostly very irregular and the plants are highly sterile. A very variable number of bivalents is formed at meiosis, ranging between the minimum $(0)$ and theoretical maximum (14) (Barker \& Stace, 1986). Since the karyotypes of $F$. rubra and $V$. fasciculata are indistinguishable by conventional staining techniques (e.g. Feulgen or orcein), all the chromosomes being similar in size and all metacentrics or submetacentrics, it is not possible to distinguish between homogenetic $(\mathrm{V}-\mathrm{V}$ or $\mathrm{F}-\mathrm{F})$ and heterogenetic (V-F) pairing at meiosis (up to 14 bivalents could form from either or both types of pairing). Bailey \& Stace (1992) investigated the Giemsa C-banded karyotypes and found that the two parental species presented different patterns. In Festuca rubra all the chromosomes have a conspicuous terminal heterochromatic block on one or both arms, such blocks being completely absent from Vulpia fasciculata. Weak interstitial or centromeric bands are present in most of the Vulpia chromosomes, but not in Festuca. This difference allows the parental origin of every chromosome of the $\mathrm{F}_{1}$ hybrid $\times$ Festulpia to be determined at both mitosis and meiosis (Bailey \& Stace, 1992), and demonstrates unequivocally that both homogenetic and heterogenetic pairing occurs, roughly in the ratio 3:1 (Bailey \& Stace, 1992).

Although the $F_{1}$ hybrid is highly sterile, a small amount of seed is set (almost certainly via backcrossing to male $F$. rubra) and mature plants can be raised. One plant examined in detail by Stace \& Ainscough (1984) proved to be hexaploid with a near-regular meiosis (19-21 bivalents) and a reasonably high seed-set. This plant resembles normal $F$. rubra closely, but differs in a few quantitative characters that are matched by some wild hexaploids growing in maritime sand near populations of Vulpia fasciculata. The existence of such plants demonstrates a mechanism for the introgression of Vulpia fasciculata into Festuca rubra, so increasing the variability of the latter. Presumably, the cytoplasm of these backcross derivatives is essentially that of Vulpia, and up to 14 of the chromosomes (but possibly many fewer) contain Vulpia genes. However, all of the 42 chromosomes have one or two terminal Festucaderived bands (Bailey \& Stace, 1992). Possibly, interstitial segments of Vulpia chromosomes are integrated into the genome, but the pattern of $\mathrm{C}$-banding in the two parents is inadequate to demonstrate it. Hence, a reliable marker for the entire length of each Vulpia chromosome is needed.

Genomic in situ hybridization (GISH) provides a direct, visual method of distinguishing entire parental genomes in both intergeneric (Schwarzacher et al., 1989; Anamthawat-Jónsson et al., 1990; Leitch et al., 1991) and interspecific (Schwarzacher et al., 1992a; Parokonny et al., 1992a) man-made hybrids in plants. As a physical marker for whole genomes, GISH has been used to identify alien chromosomes or chromosome segments in wheat (Heslop-Harrison et al., 1990; Mukai \& Gill, 1991; Schwarzacher et al., 1992b), to examine genome reorganization in asymmetric somatic hybrids (Parokonny et al., 1992b), and to test genome homology for studying plant evolution and biosystematics (Bennett et al., 1992; Kenton et al., 1993).

We aim to use GISH to test the hypothesis that Vulpia chromatin has been transferred into Festuca rubra populations by introgressive hybridization. The present paper reports the results of experiments to assess whether GISH can reliably discriminate between Vulpia and Festuca chromosomes in both somatic and meiotic nuclei of $\times F$. hubbardii.

\section{Materials and methods}

\section{Plant material}

Plants of Festuca rubra, Vulpia fasciculata and their $\mathrm{F}_{1}$ hybrid $\times$ Festulpia hubbardii, were obtained from natural sources (Table 1). These have formed the basis of previous studies (Stace \& Cotton, 1974; Stace \& Ainscough, 1984; Ainscough et al., 1986; Bailey \& Stace, 1992), and have subsequently been cultivated at the Department of Botany, University of Leicester.

Actively growing root tips were pre-treated in saturated $\alpha$-bromonaphthalene at $4^{\circ} \mathrm{C}$ for $22 \mathrm{~h}$, and fixed and subsequently stored in $3: 1(\mathrm{v} / \mathrm{v})$ absolute ethanol:glacial acetic acid at $4^{\circ} \mathrm{C}$.

\section{Preparation of chromosome spreads}

Air-dried mitotic spreads were prepared by physically removing meristematic tissue from fixed root tips using tungsten needles and without prior enzyme hydrolysis. Meiotic spreads were made from the anther contents of fixed inflorescences as described by Bailey \& Stace (1992). Care was taken to minimize exposure of fixed anthers to ambient conditions by storing florets awaiting dissection on solid carbon dioxide covered with ice. Anthers of the required size for meiosis were quickly stripped out and stored on the same cold plate in a 
Table 1 Origin and chromosome numbers of the material used in this study

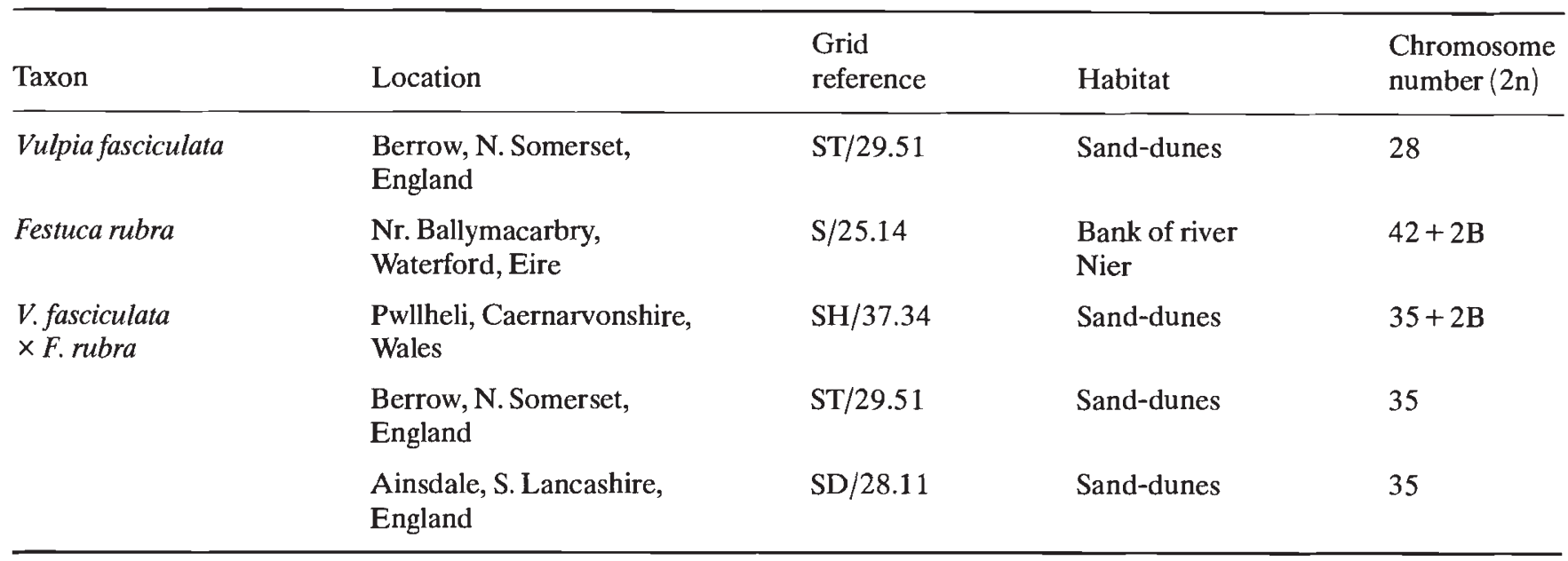

sealed bijou bottle. Coverslips of both mitotic and meiotic preparations were removed using solid carbon dioxide (Conger \& Fairchild, 1953). Slides were airdried before being stored in a vacuum desiccator at $4^{\circ} \mathrm{C}$ for up to several weeks.

Prior to in situ hybridization, and usually the evening before, slides were re-fixed in 45 per cent acetic acid for $10 \mathrm{~min}$, washed in absolute ethanol twice, $10 \mathrm{~min}$ each, and dried in an oven overnight at $42^{\circ} \mathrm{C}$. Slides were then treated with $100 \mu \mathrm{g} \mathrm{ml}^{-1}$ of DNase-free RNase in $2 \times \mathrm{SSC}(0.3 \mathrm{M} \mathrm{NaCl}, 0.03 \mathrm{~m}$ sodium citrate, $p \mathrm{H} 7)$ for $1 \mathrm{~h}$ at $37^{\circ} \mathrm{C}$ in a moist chamber, washed thrice in $2 \times \mathrm{SSC}, 5 \mathrm{~min}$ each, dehydrated through an ethanol series ( 70 per cent, 80 per cent, absolute (twice), 5 min each) on ice, and dried in an oven at $42^{\circ} \mathrm{C}$

\section{Genomic probe preparation and in situ hybridization}

Genomic DNA was extracted from $0.5-1.0 \mathrm{~g}$ of fresh leaf material using the CTAB method of Doyle \& Doyle (1987) and mechanically sheared to give fragments largely in the range of $10-12 \mathrm{~kb}$, as assessed using gel electrophoresis. For use as a probe, $2-3 \mu \mathrm{g}$ were labelled with biotin-14-dATP by nick translation using a modified version of the manufacturer's (GIBCO BRL BioNick Labeling System) protocol; essentially ethanol precipitation was performed only once to reduce DNA loss, and the DNA pellet was washed in 70 per cent ethanol prior to drying before resuspension in TE $(10 \mathrm{~mm}$ Tris- $\mathrm{HCl}, 1 \mathrm{~mm}$ EDTA, $p \mathrm{H} \mathrm{8.0)}$. Total genomic DNA from each of the parental species, Festuca rubra and Vulpia fasciculata, was autoclaved for $5 \mathrm{~min}$ to give DNA fragments of about
100-250 bp long to be used as blocking DNA (cf Anamthawat-Jónsson et al., 1990).

Genomic in situ hybridization was as described by Bennett et al. (1992) with only minor modifications. Chromosomal DNA on the slides was denatured by immersion in 70 per cent de-ionized formamide (Fisons, electrophoresis grade), 30 per cent $2 \times \mathrm{SSC}$ at $68-72^{\circ} \mathrm{C}$ for $2 \mathrm{~min}$. Slides were then rapidly dehydrated in an ethanol series ( 70 per cent, 80 per cent, absolute (twice), 2 min each) at $-20^{\circ} \mathrm{C}$ (from Mukai $e t$ al., 1991) and air-dried. The probe mix containing 5-10 $\mu \mathrm{g} \mathrm{ml}^{-1}$ biotinylated genomic DNA, 50 per cent $(\mathrm{v} / \mathrm{v})$ de-ionized formamide, 10 per cent $(\mathrm{w} / \mathrm{v})$ dextran sulphate, $900 \mu \mathrm{g} \mathrm{ml}^{-1}$ sonicated salmon sperm DNA, $50-100 \mu \mathrm{g} \mathrm{ml}^{-1}$ blocking DNA ( $c f$. AnamthawatJónsson et al., 1990), and $0.3 \mathrm{M} \mathrm{NaCl}$, was denatured at $76^{\circ} \mathrm{C}$ for $15 \mathrm{~min}$, and then immediately quenched on ice for 2-5 min. Twenty microlitres were applied to each slide and covered with a plastic coverslip. DNA-DNA in situ hybridization was carried out overnight in a moist chamber at $37^{\circ} \mathrm{C}$. Following hybridization the slides were washed in $2 \times \mathrm{SSC}$ at $42^{\circ} \mathrm{C}, 50$ per cent $(\mathrm{v} / \mathrm{v})$ de-ionized formamide in $2 \times \mathrm{SSC}$ at $42^{\circ} \mathrm{C}$, $2 \times \mathrm{SSC}$ at $42^{\circ} \mathrm{C}$, and $2 \times \mathrm{SSC}$ at room temperature, 10 min each. According to Schwarzacher et al. (1989), these conditions allow hybridization between DNAs sharing at least $80-85$ per cent sequence identity, assuming that the parameters affecting nucleic acid hybridization in solution can be applied to chromosomal DNA in situ (Meinkoth \& Wahl, 1984). Biotinylated DNA was detected with $5 \mu \mathrm{g} \mathrm{ml} \mathrm{m}^{-1}$ fluoresceinated (FITC) avidin (Vector Laboratories) and amplified once with $25 \mu \mathrm{g} \mathrm{ml}^{-1}$ biotinylated antiavidin $\mathrm{D}$ followed by $10 \mu \mathrm{g} \mathrm{ml}^{-1}$ fluoresceinated 
avidin as described by Schwarzacher et al. (1989). Chromatin was counterstained using 1-2 $\mu \mathrm{g} \mathrm{ml}^{-1}$ of the non-specific fluorochrome propidium iodide, and the differentiating fluorochrome DAPI $\left(4^{\prime}, 6\right.$-diamidino-2-phenylindole), which highlights AT-rich heterochromatin (Schweizer, 1976). The in situ hybridization signal and propidium iodide were excited with blue light (450-490 nm), and detected by their yellow and red fluorescence, respectively. DAPI fluorescence was visualized after excitation with ultraviolet light (near $365 \mathrm{~nm}$ ). Photographs were taken with Kodak Ektachrome P800/1600 Colour Reversal Film, processed at 800 ASA.

\section{Results}

DAPI-stained chromosome spreads of hybrid mitotic metaphases after in situ hybridization (Fig. 1a) showed that 21 of the 35 chromosomes had brightly fluorescing, DAPI-positive bands located distally on either one or both chromosome arms. The other 14 chromosomes, and the two B chromosomes when present, each had largely uniform DAPI fluorescence, although in the former some small, faintly fluorescing bands were seen occasionally about the centromeric region of some chromosomes. DAPI staining in $\times F$. hubbardii, therefore, gave a very similar chromosome banding profile to that found with Giemsa C-banding by Bailey \& Stace (1992). Thus, in the present experiments, the 21 chromosomes with brightly fluorescing, terminal, DAPI-positive bands were derived from $F$. rubra. Of the chromosomes lacking conspicuous DAPI-positive bands, the two smallest, when present, were B chromosomes probably from $F$. rubra, and the 14 larger were derived from $V$. fasciculata.

Figure 1(a) and (b) shows fluorescent micrographs of the same somatic root tip spread of $\times$ Festulpia hubbardii. Biotinylated genomic DNA from $V$. fascicu$l a t a$, mixed with an excess of unlabelled DNA from $F$. rubra, hybridized preferentially in situ to practically the entire length of the Vulpia chromosomes, as revealed by their yellow fluorescence (Fig. 1b, c and e). This GISH probe also hybridized partially along the euchromatic regions of the Festuca chromosomes, which fluoresced a dull orange-yellow (Fig. 1b and c). The red fluorescence seen at those regions of the Festuca chromosomes coinciding with the DAPI-positive blocks ( $c f$. Fig. 1c and d), indicated little or no hybridization of the Vulpia genomic probe to such AT-rich heterochromatic segments. This pattern of hybridization occurred at all stages of mitosis (e.g. Fig. 1e), and also at interphase. In a reciprocal GISH (Fig. $1 \mathrm{f})$, using labelled $F$. rubra DNA as a probe with an excess of unlabelled $V$. fasciculata DNA block, the reverse result was obtained. This time, the Festuca probe hybridized more strongly to heterochromatic than to euchromatic regions of the Festuca chromosomes, implying that the euchromatic regions were preferentially blocked by the unlabelled Vulpia DNA (cf. Anamthawat-Jónsson et al., 1990). Vulpia chromosomes fluoresced red owing to the lack of hybridization signal, coupled with the relative increase in the amount of propidium iodide staining in this particular experiment.

The Vulpia probe was used in a subsequent GISH experiment with a view to discriminating between homogenetic (Vulpia-Vulpia and Festuca-Festuca) and heterogenetic (Vulpia-Festuca) chromosome associations at first meiotic metaphase in $\times$ Festulpia hubbardii (Fig. 1g-j). Vulpia and Festuca chromosomes, as at mitosis, fluoresced yellow and red, respectively. Homogenetic bivalents were identified unequivocally by their colour. Those involving only Festuca chromosomes were red (Fig. $1 \mathrm{~g}$ and i), while

Fig. 1 (opposite) Fluorescent micrographs of root tip $(a-f)$ and meiotic $(g-j)$ chromosome preparations of $\times$ Festulpia hubbardii after GISH. Sites of probe hybridization fluoresce yellow, while unprobed sites fluoresce red. (a-e and $\mathrm{g}-\mathrm{j}$ ) Pwllheli hybrid, (f) Ainsdale hybrid (see Table 1). (a and b) The same mitotic metaphase cell stained with DAPI (a) and probed with biotinylated genomic DNA from $V$. fasciculata mixed with excess unlabelled total genomic DNA from $F$. rubra (b). B chromosomes are arrowed. (c and d) Individual chromosomes derived from $V$. fasciculata and $F$. rubra showing the characteristic hybridization pattern of the Vulpia genomic probe (c), and stained with DAPI (d). Note uniform labelling of the Vulpia chromosome, except for at the centromeric region coinciding with a faint DAPI-positive segment (arrowed in d), and the relative absence of probe hybridization signal at the terminal region of the Festuca chromosome (arrowed in c) coinciding with DAPI-positive heterochromatin (arrowed in d). (e) Prometaphase cell probed with the same Vulpia genomic probe with 14 Vulpia chromosomes labelled. (f) Metaphase cell probed with biotinylated total genomic DNA from $F$. rubra mixed with an excess of unlabelled total genomic DNA from $V$. fasciculata. Note preferential probe hybridization to the terminal regions of the Festuca chromosomes. (g-j) Two meiotic first metaphase spreads probed with a Vulpia genomic probe ( $\mathrm{g}$ and $\mathrm{i}$ ), and after GISH stained with DAPI $(\mathrm{h}$ and $\mathrm{j})$, showing homogenetic $(\mathrm{V}-\mathrm{V}$ and $\mathrm{F}-\mathrm{F})$ and heterogenetic $(\mathrm{V}-\mathrm{F})$ bivalents, labelled accordingly. Scale $=10 \mu \mathrm{m}(\mathrm{a}$ and $\mathrm{b}$, $\mathrm{e}-\mathrm{j})$, and $5 \mu \mathrm{m}$ (c and $\mathrm{d})$. 

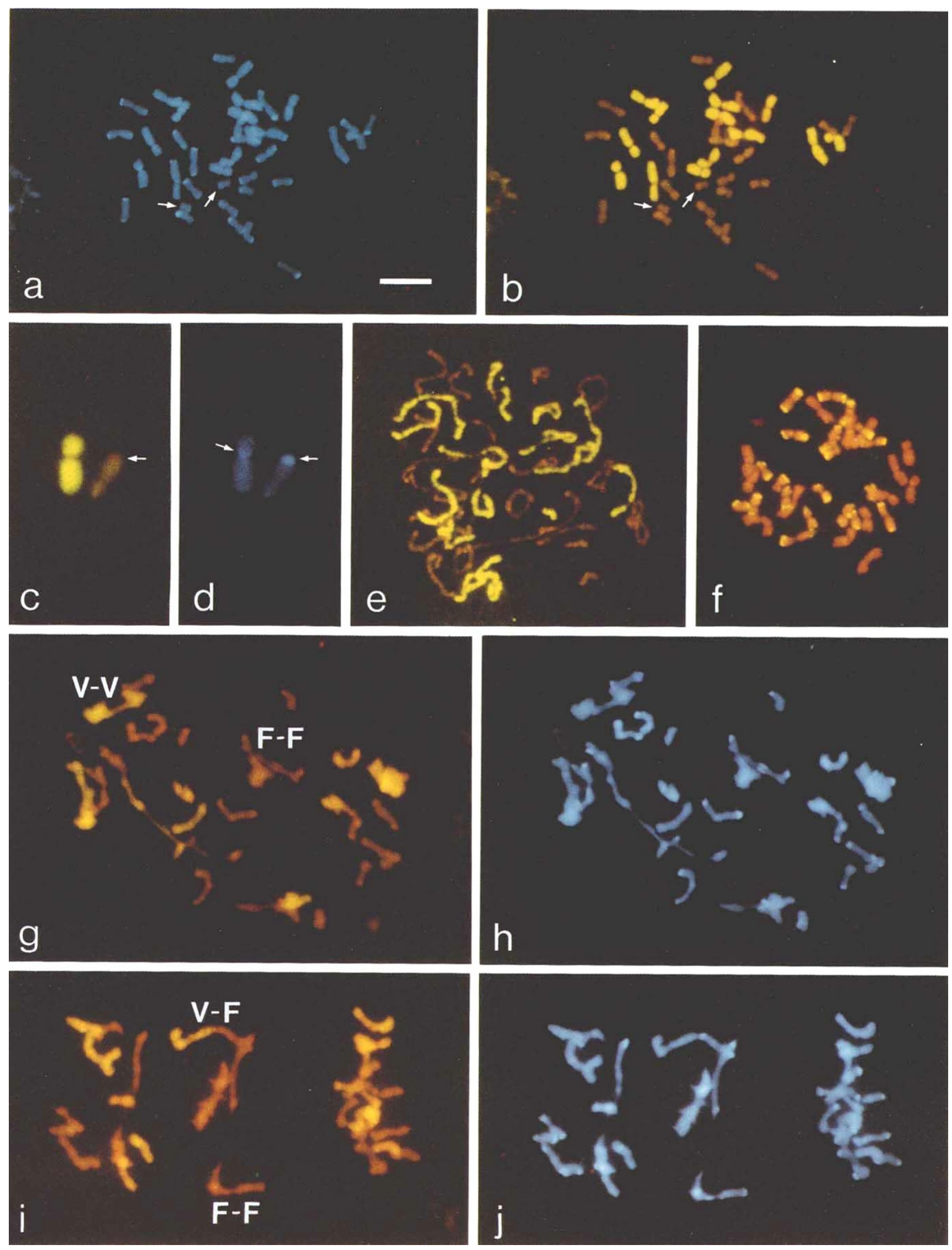
Vulpia-Vulpia bivalents were yellow (Fig. 1g). Heterogenetic bivalents were bi-coloured with red (Festuca) and yellow (Vulpia) components (Fig. 1i). Unlike the case with mitotic spreads, the DAPI-positive bands on the Festuca chromosomes were sometimes not visible at first meiotic metaphase (Fig. $1 \mathrm{~h}$ and $\mathrm{j}$ ). In such cases the parental chromosomes could be identified only by GISH.

\section{Discussion}

Our results show that GISH offers a reliable means of discriminating between chromosomes derived from Vulpia fasciculata and Festuca rubra in their naturally occurring $\mathrm{F}_{1}$ hybrid $\times$ Festulpia hubbardii. Moreover, Vulpia chromatin could be unambiguously identified by its yellow fluorescence in both somatic and meiotic nuclei. Unlike Giemsa C-banding, where the Vulpia and Festuca chromosomes could be distinguished only by the respective absence or presence of terminal heterochromatic blocks on at least one chromosome arm (Bailey \& Stace, 1992), genomic probing provides a colour-coded, physical marker for virtually the entire length of every $V$. fasciculata chromosome. Despite the use of excess unlabelled $F$. rubra genomic DNA to suppress non-specific binding, there was some hybridization of the Vulpia probe to the Festuca chromosomes. This implies the occurrence of DNA sequences common to $V$. fasciculata dispersed throughout, and in particular along euchromatic regions of, the Festuca genome. Given that these species produce sexual hybrids in nature, in which up to the theoretical maximum of 14 bivalents can occur at meiosis (Stace \& Cotton, 1974) (albeit usually far fewer), a considerable degree of genomic homology is not surprising. However, there was apparently little hybridization of the Vulpia probe to the terminal heterochromatic regions of the Festuca chromosomes. This may be owing to either the physical inaccessibility of the Vulpia probe at these sites of highly condensed DNA, or sequence dissimilarity between the $V$. fasciculata genomic probe and the $F$. rubra terminal heterochromatin. However, as genomic DNA from $F$. rubra hybridized preferentially to the terminal heterochromatic blocks of the Festuca chromosomes in a reciprocal GISH, the physical inaccessibility explanation seems highly unlikely. Instead, the most feasible interpretation is that these terminal regions of the Festuca chromosomes comprise localized, Festuca-specific repeated DNA sequences, similar to the species-specific repeats found near telomeres in other grasses such as Secale cereale (e.g. McIntyre et al., 1990). So, GISH can provide not only physical markers for identifying any point along the length of the Vulpia genome in $\times$ Festulpia hubbardii, but also an insight into the physical organization of both the Vulpia and Festuca chromosomes.

A direct method of assessing inter-genomic homologies is to analyse hybrid meiotic chromosome behaviour in terms of the frequency of heterogenetic bivalents (i.e. V-F pairing in our material). However, where at least one of the parents is polyploid and where the chromosomes are all similar in size and morphology, and lack distinctive markers, this may be difficult or even impossible. The occurrence of both homogenetic and heterogenetic pairing can be sometimes safely inferred because the number of bivalents formed exceeds the number that could result from either form of pairing alone. In tetraploid hybrids between Lolium perenne $(2 n=2 x=14)$ and Festuca rubra or $F$. arundinacea $(2 n=6 x=42)$, only seven bivalents could form from either homogenetic or heterogenetic pairing. Jauhar (1975) and Evans \& Taing Aung (1986) found numbers of bivalents closer to 14 than to 7 in $L$. perenne $\times F$. rubra and in $L$. perenne $\times F$. arundinacea respectively, proving the occurrence of both forms of pairing. However, in triploid hybrids between diploids and tetraploids, or in pentaploid hybrids between tetraploids and hexaploids, no such inference can be made, because the maximum number of bivalents possible ( $x$ and $2 x$, respectively) can be accounted for by one form of pairing alone. In such cases, the parental origin of each chromosome needs to be determined. Previously, this was impossible. However, as we have shown, GISH provides the necessary discrimination. In $\times$ Festulpia hubbardii GISH permitted the precise characterization of bivalents at first meiotic metaphase. Although the bivalent frequency in the present material was low, with only one or two bivalents per cell, both homogenetic and heterogenetic bivalents were clearly recognized. Thus, GISH has clear potential scope in aiding chromosome recognition in meiotic as well as mitotic nuclei.

Despite being closely related, there appear to be enough different dispersed DNA sequences in $V$. fasciculata and $F$. rubra genomes to permit their discrimination in their naturally occurring $F_{1}$ hybrid. Previously, genomic probing has distinguished genetically similar genomes in Hordeum vulgare $\times$ H. bulbosum (Schwarzacher et al., 1992a) and in Gibasis karwinskyana $\times$ G. consubrina (Parokonny et al., 1992a). Thus, our results provide a further successful example of GISH for identifying parental chromosomes, here in a wild hybrid, between closely related plant species.

Our ultimate aim is to test whether Vulpia chromatin has been transferred into Festuca rubra populations by introgressive hybridization, through backcrossing of the pentaploid $\mathrm{F}_{1} \times F$. hubbardii to male hexaploid $F$. 
rubra. The present results show that GISH will probably provide the necessary means to carry out this investigation. However, what will be an important question, noted previously by both Schwarzacher et al. (1992b) and Parokonny et al. (1992a), concerns the limitations of GISH. Is GISH sensitive enough to detect small introgressed segments of Vulpia chromatin and, if so, down to what size limit? Although sufficiently sensitive to detect alien chromosomes or chromosome segments in wheat (Heslop-Harrison et al., 1990; Mukai \& Gill, 1991; Schwarzacher et al., 1992b), 'relatively small' regions of homology between the genomes of closely related species (Parokonny et al., 1992a; Kenton et al., 1993), and intergenomic translocations in asymmetric somatic hybrids (Parokonny et al., 1992b), the finer limits of genomic probing remain unresolved. Further experiments with both $\times$ Festulpia and other wild hybrids should provide important new insights into the process of introgressive hybridization in nature and its importance in plant genome evolution and speciation.

\section{Acknowledgements}

STB and MDB thank BP Venture Research for support. GISH experiments were performed at the Jodrell Laboratory, RBG, Kew.

\section{References}

AINSCOUGH, M. M., BARKER, C. M. AND STACE, C. A. 1986. Natural hybrids between Festuca and species of Vulpia section Vulpia. Watsonia, 16, 143-151.

ANAMTHAWAT-JONSSON, K., SCHWARZACHER, T., LEITCH, A. R., BENNETT, M. D. AND HESLOP-HARRISON, J. S. 1990. Discrimination between closely related Triticeae species using genomic DNA as a probe. Theor. Appl. Genet., 79, 721-728.

AUQUIER, P. 1977. Biologie de la reproduction dans le genre Festuca L. (Poaceae) I. Systemes de pollinisation. Bull. Soc. Roy. Bot. Belg., 110, 129-150.

BAILEY, J. P. AND STACE, C. A. 1992. Chromosome banding and pairing behaviour in Festuca and Vulpia (Poaceae, Pooideae). Pl. Syst. Evol., 182, 21-28.

BARKER, C. M. AND STACE, c. A. 1986. Hybridization in the genera Vulpia and Festuca (Poaceae): meiotic behaviour of artificial hybrids. Nord. J. Bot., 6, 1-10.

BENNETT, S. T., KENTON, A. Y. AND BENNETT, M. D. 1992. Genomic in situ hybridization reveals the allopolyploid nature of Milium montianum (Gramineae). Chromosoma, 101, 420-424.

CONGER, A. D. AND FAIRCHILD, L. M. 1953. A quick-freeze method for making smear slides permanent. Stain Technol., 28, 281-283.
DOYLE, J. J. AND Doyle, J. L. 1987. A rapid DNA isolation procedure for small quantities of fresh leaf tissue. Phytochem. Bull., 19, 11-15.

EVANS, G. M. AND TAING AUNG. 1986. The influence of the genotype of Lolium perenne on homoeologous chromosome association in hexaploid Festuca arundinacea. Heredity, 56, 97-103.

HESLOP-HARRISON, J. S., LEITCH, A. R., SCHWARZACHER, T. AND ANAMTHAWAT-JÓNSSON, K. 1990. Detection and characterization of $1 \mathrm{~B} / 1 \mathrm{R}$ translocations in hexaploid wheat. Heredity, 65, 356-362.

IAUHAR, P. P. 1975. Genetic regulation of diploid-like chromosome pairing in the hexaploid species Festuca arundinacea Schreb. and F. rubra L. (Gramineae). Chromosoma, 52, 363-382.

KENTON, A. Y., PAROKONNY, A. S., BENNETT, S. T. AND BENNETT, M. D. 1993. Does genome organization influence speciation? A reappraisal of karyotype studies in evolutionary biology. In: Lees, D. R. and Edwards, D. (eds) Evolutionary Patterns and Processes, Linnean Society Symposium Series No. 14, Academic Press, London, pp. 189-206.

LEITCH, A. R., SCHWARZACHER, T., MOSGÖLLER, W., BENNETT, M. D. AND HESLOP-HARRISON, J. S. 1991. Parental genomes are separated throughout the cell cycle in a plant hybrid. Chromosoma, 101, 206-213.

MCINTYRE, C. L., PEREIRA, S., MORAN, L. B. AND APPELS, R. 1990. New Secale cereale (rye) DNA derivatives for the detection of rye chromosome segments in wheat. Genome, 33, $635-640$.

MEINKOTH, J. AND WAHL, G. 1984. Hybridization of nucleic acid immobilized on solid supports. Anal. Biochem., 138, 267-284.

MUKAI, Y., ENDO, T. R. AND GILl, B. S. 1991. Physical mapping of the $18 \mathrm{~S} .26 \mathrm{~S}$ rRNA multigene family in common wheat: Identification of a new locus. Chromosoma, 100, 71-78.

MUKAI, Y. AND GILL, B. S. 1991. Detection of barley chromatin added to wheat by genomic in situ hybridization. Genome, 34, 448-452.

PAROKONNY, A. S., KENTON, A. Y., MEREDITH, L., OWENS, S. J. AND BENNETT, M. D. 1992a. Genomic divergence of allopatric sibling species studied by molecular cytogenetics of their $\mathrm{F}_{1}$ hybrids. Plant J., 2, 695-704.

PAROKONNY, A. S., KENTON, A. Y., GLEBA, Y. Y. AND BENNETT, M. D. 1992b. Genome reorganization in Nicotiana asymmetric somatic hybrids analysed by in situ hybridization. Plant J., 2, 863-874.

SCHWARZACHER, T., LEITCH, A. R., BENNETT, M. D. AND HESLOPHARRISON, J. S. 1989. In situ localization of parental genomes in a wild hybrid. Ann. Bot., 64, 315-324.

SCHWARZACHER, T., HESLOP-HARRISON, J. S., ANAMTHAWAT-JONSSON, K., FINCH, R. A. AND BENNETT, M. D. 1992a. Parental genome separation in reconstructions of somatic and premeiotic metaphases of Hordeum vulgare $\times H$. bulbosum. J. Cell. Sci., 101, 13-24.

SCHWARZACHER, T., ANAMTHAWAT-JÓNSSON, K., HARRISON, G. E. ISLAM, A. K. M. R., JIA, J. Z., KING, I. P., LEITCH, A. R., MILLER, T. E., READER, S. M., ROGERS, W. J., SHI, M. AND HESLOP-HARRISON, J. S. 1992 b. Genomic in situ hybridization to identify alien 
chromosomes or chromosome segments in wheat. Theor. Appl. Genet., 84, 778-786.

SCHWEIZER, D. 1976. Reverse fluorescent chromosome banding with chromomycin and DAPI. Chromosoma, 58, 307-324.

STACE, C. A. 1991. New Flora of the British Isles. Cambridge University Press, Cambridge, p. 1012.
STACE, C. A. AND AINSCOUGH, M. M. 1984. Continuing addition to the gene-pool of the Festuca rubra aggregate (Poaceae: Poeae). Pl. Syst. Evol., 147, 227-236.

STACE, C. A. AND COTTON, R. 1974. Hybrids between Festuca rubra L. sensu lato and Vulpia membranacea (L.) Dum. Watsonia, 10, 119-138. 